\title{
Estudo das Propriedades de Compósitos de Polianilina e Resina Epoxídica
}

\author{
Thiago P. Amaral, Guilherme M. O. Barra, Fabio L. Barcia, Bluma G. Soares \\ Instituto de Macromoléculas Professora Eloisa Mano, UFRJ
}

\begin{abstract}
Resumo: Compósitos condutores de eletricidade envolvendo polianilina e resina epoxídica foram preparados utilizando-se o método da polimerização in situ. O método consiste da polimerização em emulsão da anilina na presença da resina epoxídica. Ácido dodecilbenzenossulfônico foi utilizado como agente dopante, que age também como surfactante da polimerização em emulsão. A condutividade elétrica do sistema Pani/resina epoxídica alcançou valores tão altos quanto $2 \times 10^{-3} \mathrm{~S} / \mathrm{cm}$, com uma concentração de Pani correspondente a $7 \%$ em peso. O conteúdo de Pani na mistura foi determinado por análise elementar. $\mathrm{O}$ efeito do método de cura da resina epoxídica na condutividade elétrica, temperatura de transição vítrea e propriedades mecânicas do sistema foi também investigado.
\end{abstract}

Palavras-chave: Polianilina, compósitos condutores, condutividade elétrica, resina epoxídica.

\section{Polyaniline/Epoxy Resin Conducting Blend}

Abstract: The conductive composites of polyaniline (Pani) and epoxy resin were prepared by polymerization of aniline in the presence of epoxy resin, using a direct, one step in situ polymerization method. The polymerization of aniline was performed in an emulsion system comprising water and toluene containing epoxy resin in the presence of dodecylbenzene sulfonic acid, which acts as surfactant and a dopant for Pani. The electrical conductivity of Pani/ epoxy resin reached values as high as $2 \times 10^{-3} \mathrm{~S} / \mathrm{cm}$ at a Pani content corresponding of $7 \mathrm{wt} \%$ of Pani. The Pani content in the mixtures was calculated by means of elemental analysis. The relationships between glass transition temperature (Tg) and Pani.DBSA content obtained by two different cured methods were also investigated.

Keywords: Polyaniline, conducting composites, electrical conductivity, epoxy resin.

\section{Introdução}

$\mathrm{O}$ aumento da demanda de materiais condutores de eletricidade com boas propriedades mecânicas tem despertado o interesse de diversos grupos de pesquisa para o desenvolvimento de sistemas constituídos por partículas de polímeros condutores dispersas em matrizes poliméricas isolantes. Esta estratégia é muito interessante do ponto de vista tecnológico porque o material final é capaz de combinar a condutividade elétrica dos polímeros condutores e as boas propriedades mecânicas e processabilidade dos polímeros convencionais $^{[1-4]}$.

Dentre os polímeros condutores, a polianilina (Pani) tem se mostrado um dos mais versáteis devido à facilidade da polimerização, à boa estabilidade térmica e à possibilidade de ser facilmente transformada na forma condutora a partir da protonação com ácidos fortes ${ }^{[5]}$. A polianilina protonada com ácidos minerais, como ácido clorídrico e ácido sulfúrico, é praticamente insolúvel na maioria dos solventes orgânicos e se dispersa na matriz polimérica convencional como se fosse uma carga inorgânica, devido à total falta de compatibilidade. O desenvolvimento de técnicas de protonação (dopagem) utilizando ácidos protônicos funcionalizados (tais como ácido dodecilbenzenossulfônico, DBSA e ácido canforsulfônico, CSA) acarretou um progresso significante nessa área, devido ao aumento na processabilidade e melhora na solubilidade em

Autor para correspondência: Bluma G. Soares, Instituto de Macromoléculas Professora Eloisa Mano, UFRJ, C.P.: 68525, CEP: 21945-970, Rio de Janeiro, RJ. E-mail: bluma@ima.ufri.br 
solventes convencionais ${ }^{[6]}$. Por exemplo, a Pani dopada com DBSA (Pani.DBSA) tem sido utilizada na preparação de várias misturas, tanto no estado fundido como em solução. Alguns exemplos na literatura de polímeros convencionais misturados à Pani.DBSA no estado fundido incluem: poliolefinas $^{[7-9]}$, poliestireno ${ }^{[10]}, \mathrm{SBS}^{[11-12]}, \mathrm{EVA}^{[13]}$ e vários elastômeros vulcanizados ${ }^{[14-16]}$.

Misturas em solução também têm sido bastante estudadas, principalmente com a utilização de Pani dopada com ácido canforsulfônico em matrizes de PMMA, devido à grande solubilidade de ambos em $\mathrm{m}$-cresol[ ${ }^{[4,9,17]}$. Além dessas duas técnicas, outro método que tem recebido atenção especial consiste na polimerização em emulsão da anilina na presença do polímero isolante ${ }^{[4,18-21]}$.

A resina epoxídica é um polímero termorrígido bastante utilizado como matriz curada na preparação de materiais compósitos, principalmente devido às suas excelentes propriedades, tais como, estabilidade térmica, resistência a solventes, boa adesão, entre outras. Estas propriedades estão diretamente relacionadas à escolha do agente e do ciclo de cura. A maioria dos compósitos de resina epoxídica citados na literatura, busca a melhoria da resistência da resina à fratura, por meio do aumento do seu fator crítico de intensidade de tensão $\left(\mathrm{K}_{\mathrm{IC}}\right)$. A adição de agentes tenacificantes ou flexibilizantes, que podem ser elastômeros líquidos funcionalizado ou polímeros termoplásticos, constitue a forma mais clássica de melhoria das propriedades de fratura da resina epoxídica ${ }^{[22,23]}$.

O estudo de misturas contendo polímero condutor disperso em uma matriz termorrígida, como a resina epoxídica tem como vantagem o possível desenvolvimento de materiais com propriedades condutoras, que pode ser aplicado em revestimentos capazes de dissipar cargas de natureza eletrostática, revestimentos anticorrosivos, adesivos condutores, entre outras aplicações ${ }^{[24]}$. Alguns trabalhos encontrados na literatura, utilizam a mistura física entre polipirrol e resina epoxídica ${ }^{[24-25]}$. Revestimento a base de polianilina com resina epoxídica, com propriedades anti-corrosivas, foi também desenvolvido a partir de mistura em solução envolvendo a polianilina dopada com ácido canforssulfônico e resina epoxídica ${ }^{[26]}$.

O trabalho apresentado a seguir relata a preparação de misturas envolvendo Pani e resina epoxídica a partir de um processo em uma única etapa, denominado polimerização in situ. Este processo envolve a polimerização em emulsão do sal de anilina na presença da resina epoxídica, utilizando-se como iniciador o persulfato de amônio. Misturas homogêneas contendo $7 \%$, em peso de Pani com condutividade elétrica da ordem de $10^{-3} \mathrm{~S} / \mathrm{cm}$ foram obtidas. O trabalho inclui ainda estudos morfológicos das misturas obtidas a partir de microscopia eletrônica de varredura além de testes mecânicos e dinâmico-mecânicos.

\section{Experimental}

\section{Materiais}

A resina epoxídica utilizada neste trabalho foi a DER 331 (DOW Química), contendo 192eq/g de grupos epoxídicos. Anilina (Merck), persulfato de amônio $\left(\mathrm{NH}_{4}\right)_{2} \mathrm{~S}_{2} \mathrm{O}_{8}$ (Merck, grau analítico) e ácido dodecil benzeno sulfônico, DBSA (Pro-Química do Brasil, grau técnico), foram utilizados sem prévia purificação.

\section{Preparação do sal de anilina.DBSA (DBSAn)}

$O$ sal de anilina.DBSA foi preparado misturandose $10 \mathrm{ml}$ de anilina e $30 \mathrm{ml}$ de DBSA em um becher. $O$ sal obtido (DBSAn) foi purificado por recristalização em solução de água/metanol (razão 1:1) e seco a vácuo.

\section{Polimerização in situ da anilina na presença da} resina epoxídica

4,5 g de DBSAn foram dissolvidos em 40ml de tolueno. Em seguida, adicionou-se uma solução de resina epoxídica em $50 \mathrm{ml}$ de tolueno e o meio reacional foi mantido sob agitação mecânica a $0^{\circ} \mathrm{C}$.Adicionou-se então, lentamente, uma solução de persulfato de amônio (APS) em água. Após cerca de 6h de reação, o material obtido foi lavado com água destilada, para remoção do excesso de DBSA e APS. Após sucessivas lavagens até a neutralização do meio, o tolueno foi removido a vácuo.

Para efeitos comparativos, foi preparada uma mistura física entre a resina epoxídica e Pani.DBSA (Exp.n-2), utilizando-se o mesmo procedimento e as mesmas proporções de reagentes da Exp. № 1. Esta mistura foi preparada minutos antes de se adicionar $o$ agente de cura.

As misturas foram curadas a $70^{\circ} \mathrm{C}$ e a $100^{\circ} \mathrm{C}$ por $24 \mathrm{~h}$ com endurecedor do tipo amina e anidrido, respectivamente 


\section{Caracterização e testes mecânicos}

A resina, a Pani pura e os compósitos foram caracterizados por diversos métodos. A caracterização qualitativa de grupos funcionais, característicos de cada material, foi realizada por meio de espectrometria de absorção no infravermelho - FTIR Perkin-Elmer 1720, utilizando célula de $\mathrm{KBr}$ e resolução de $2.00 \mathrm{~cm}^{-1}$.

A concentração de Pani nos compósitos foi determinada por gravimetria e por análise elementar CHN.

As análises dinâmico-mecânicas (DMTA) foram realizadas em um Rheometric Scientific MK3 DMTA, com freqüência de $3 \mathrm{~Hz}$ e taxa de aquecimento de $5^{\circ} \mathrm{C} /$ mim. As amostras foram preparadas em forma de barras retangulares de $2,0 \mathrm{~mm}$ de espessura.

As análises termogravimétricas (TGA) foram conduzidas em um TGA da TA Instruments, com amostras contendo cerca de $5,0 \mathrm{mg}$ e taxa de aquecimento de $10^{\circ} \mathrm{C} / \mathrm{min}$.

A morfologia das misturas obtidas foi analisada por microscopia ótica utilizando um microscópio Olympus BX 50 com aumento de 150 e 600x e Microscopia Eletrônica de Varredura (MEV), por meio de um microscópio Zeiss 960.

A condutividade elétrica foi determinada pelo método padrão 4 pontas, utilizando as misturas curadas sob a forma de filmes finos.

Os testes mecânicos foram realizados em uma máquina de tração Instron modelo 4002, com velocidade do travessão de $1 \mathrm{~mm} / \mathrm{mim}$ para ambos os testes de tração (ASTM D-638) e flexão em três pontos (ASTM D-790). Os valores apresentados constituem média de pelo menos cinco corpos de prova.

\section{Resultados e Discussão}

Preparação e caracterização das misturas

Misturas de resina epoxídica com Pani.DBSA foram preparadas a partir da polimerização in situ da anilina, utilizando razão molar APS/Ani igual a 1. A Tabela 1 compara os valores de condutividade elétrica da mistura obtida por polimerização in situ com aquela obtida por mistura física. Para a determinação da condutividade elétrica, as misturas foram previamente curadas utilizando sistema do tipo amina e do tipo anidrido.

As misturas apresentaram valores de condutividade na ordem de $10^{-3} \mathrm{~S} / \mathrm{cm}$ com apenas $7 \%$ em peso de Pani.DBSA, independente do sistema de cura empregado. Estes valores são bastante satisfatórios se comparados com aqueles obtidos por Siddaramaiah e colaboradores em sistemas envolvendo resina fenólica e polianilina ${ }^{[27]}$. Esses autores obtiveram valores de condutividade da ordem de $10^{-2} \mathrm{~S} / \mathrm{cm}$, porém com uma concentração de Pani de, no mínimo, 25\% em peso.

Comparando-se a condutividade elétrica da mistura física preparada com a mesma proporção de Pani.DBSA (Exp. № 2), a condutividade alcançada foi ligeiramente menor, sugerindo a eficiência da polimerização in situ para a obtenção de misturas condutoras com menor quantidade de Pani.

A morfologia das misturas curadas no sistema anidrido foi analisada por microscopia ótica, cujos resultados são apresentados na Figura 1. A região escura é relacionada à polianilina e a região mais clara corresponde à matriz epoxídica. Tanto a mistura preparada por polimerização "in situ" (Figura 1a) como aquela preparada a partir da mistura física (Figura 1b) apresentaram morfologias semelhantes. Todavia, naquela correspondente à polimerização in situ, a mistura é mais homogênea e os caminhos condutores são mais nítidos o que justifica a condutividade elétrica. Vale ressaltar que não foi observada mudança alguma na morfologia das misturas curadas com o sistema do tipo amina ou do tipo anidrido, concordando com os resultados de

Tabela 1. Efeito da razão molar APS/Ani na condutividade elétrica e conversão de misturas Pani.DBSA/resina epoxídica

\begin{tabular}{|c|c|c|c|c|}
\hline \multirow[t]{2}{*}{ Exp. № } & \multirow[t]{2}{*}{$\begin{array}{c}\text { APS/Ani } \\
\text { (Razão molar) }\end{array}$} & \multicolumn{2}{|c|}{$\begin{array}{l}\text { Condutividade elétrica } \\
\mathrm{S} / \mathrm{cm}\end{array}$} & \multirow{2}{*}{$\begin{array}{c}\text { Quantidade de } \\
\text { Pani.DBSA na mistura } \\
\%\end{array}$} \\
\hline & & Cura com amina ${ }^{b}$ & Cura com anidrido $^{c}$ & \\
\hline 1 & $1 / 1$ & $6,16 \times 10^{-3}$ & $3,53 \times 10^{-3}$ & 7,0 \\
\hline $2^{\mathrm{d}}$ & $1 / 1$ & $1,39 \times 10^{-3}$ & $1,04 \times 10^{-3}$ & 7,0 \\
\hline
\end{tabular}

a) conversão determinada a partir dos resultados de $\mathrm{CHN}$; b) mistura curada a $70^{\circ} \mathrm{C}$ durante $24 \mathrm{~h}$; c) mistura curada a $100^{\circ} \mathrm{C}$ durante $24 \mathrm{~h}$.; d) mistura física entre Pani.DBSA e resina epoxídica na proporção 7/93 (razão em peso) 
condutividade elétrica em ambos os sistemas de cura. A região mais clara na morfologia da mistura preparada a partir da polimerização in situ possui uma coloração ligeiramente esverdeada, mesmo após sucessivas lavagens do material com o solvente. No caso da mistura física epóxi/Pani, não se observa esta coloração esverdeada na matriz epoxídica, e sim, uma região escura correspondente à Pani e uma outra região completamente transparente e clara correspondente à matriz epoxídica.

A amostra obtida a partir da Exp. № 1 foi criofraturada e a fratura foi analisada por microscopia eletrônica de varredura. A Figura 2 apresenta esta superfície de fratura onde se observa uma excelente interação entre a matriz epoxídica e os domínios de Pani.DBSA.

As misturas foram submetidas à extração com acetona, antes do processo de cura. Este solvente é capaz de dissolver completamente a resina epoxídica não curada mas não consegue dissolver a polianilina dopada com DBSA. É importante ressaltar que, após a extração com acetona, o material solúvel proveniente da polimerização in situ apresentou uma coloração esverdeada, típica do sal de esmeraldina.
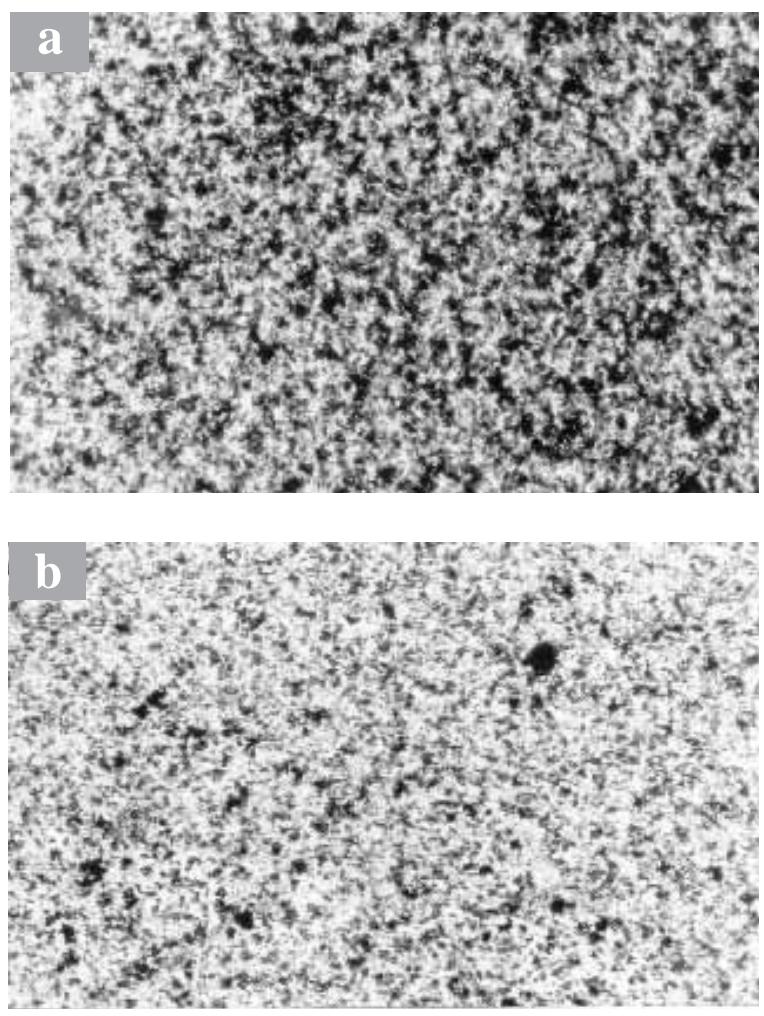

Figura 1. Microscopia ótica de filmes de misturas envolvendo resina epóxi/Pani.DBSA; (a) Exp. № 1; (b) Exp. № 4.

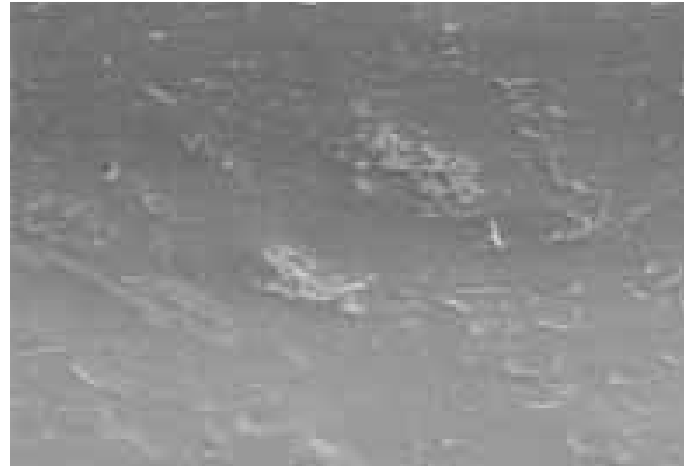

Figura 2. Micrografia obtida a partir da SEM correspondente à superfície de fratura da amostra da Exp. № 1.

O material solúvel em acetona foi precipitado em metanol e seco a vácuo, apresentando cerca de $15 \%$ de polianilina. O restante da Pani.DBSA (cerca de $85 \%$ ) permaneceu insolúvel em acetona. No caso da mistura física Pani/epoxi, o material solúvel apresentou uma coloração amarelada e translúcida, característica da resina epoxídica solubilizada em acetona. Além disso, não houve qualquer alteração no peso da amostra. Estes resultados indicam que durante a preparação da polianilina na presença da resina epoxídica (polimerização in situ), parte da anilina reagiu, através do seu grupo amina, com os anéis epoxídicos presentes na matriz, dando origem a um copolímero em bloco ou graftizado.

Tanto a mistura Pani/epóxi como os materiais de partida foram analisados por espectroscopia no infravermelho. A Figura 3 compara o espectro da mistura obtida na Exp. № 1(A) com aqueles da resina epoxídica (B) e da Pani pura (C). Os espectros das misturas e da resina epoxídica foram obtidos a partir das amostras não curadas. A banda a $910 \mathrm{~cm}^{-1}$ característica do grupo epoxídico é encontrada nas amostras de resina pura (espectro B) e na mistura Pani/ epóxi (espectro A). Além disso, observa-se nos três espectros, a absorção a $830 \mathrm{~cm}^{-1}$, característica do anel aromático. No espectro da Pani pura (espectro C), a banda larga e intensa a $1200 \mathrm{~cm}^{-1}$ é associada ao grupo $\mathrm{SO}_{3}$ presente no contra íon. Esta absorção não se encontra tão nítida no espectro da mistura, devido à sobreposição de bandas características da resina epoxídica. Outras bandas, tais como aquelas encontradas na região de $1590-1490 \mathrm{~cm}^{-1}$, atribuídas às vibrações de $\mathrm{C}-\mathrm{C}$ referentes aos anéis benzeno $\mathrm{e}$ quinona, e as bandas a $1160 \mathrm{~cm}^{-1}$, presentes na Pani pura e na mistura, associadas a vibrações do grupo $\mathrm{N}=\mathrm{C}$ correspondentes ao anel quinóide, no qual é 


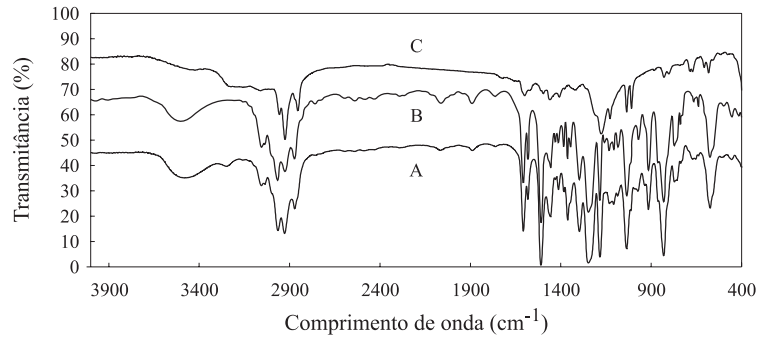

Figura 3. Espectros de FTIR da amostra obtida da Exp. № 1(A); da resina epoxídica (B) e da Pani pura (C)

atribuída a condutividade elétrica da Pani, também contribuem para caracterização das amostras contendo Pani.

Com o objetivo de avaliar possíveis interações entre a resina epoxídica e as cadeias de polianilina que se formam durante a polimerização in situ, resolveu-se normalizar os espectros, utilizando a absorção a $1298 \mathrm{~cm}^{-1}$ característica da ligação[C-O-C], que não participa da reação entre a resina epoxídica e a Pani. A partir dessa normalização, foi determinada a razão entre a absorção a $920 \mathrm{~cm}^{-1}$ relativa ao anel epoxídico com a absorção normalizada a $1298 \mathrm{~cm}^{-1}$. A Figura 4 apresenta os espectros completos da resina pura e das misturas Pani/epóxi normalizados em $1298 \mathrm{~cm}^{-1}$. As Figura 5a e 5b apresentam as regiões ampliadas dos espectros na região de 1298 e $920 \mathrm{~cm}^{-1}$. A resina epoxídica pura apresentou uma razão entre os picos de 0,86 enquanto que as Exp. № 1 e 2 apresentaram razões de 0,60 e 0,82 , respectivamente. A diminuição das razões dos picos pode ser associada à diminuição da concentração de grupos epoxídicos, ocasionado pela reação entre este grupo e aminas secundárias presentes na Pani. Como pode ser visto, a menor concentração de grupos epoxídicos encontrado na Exp. № 1 pode ser associada à formação de

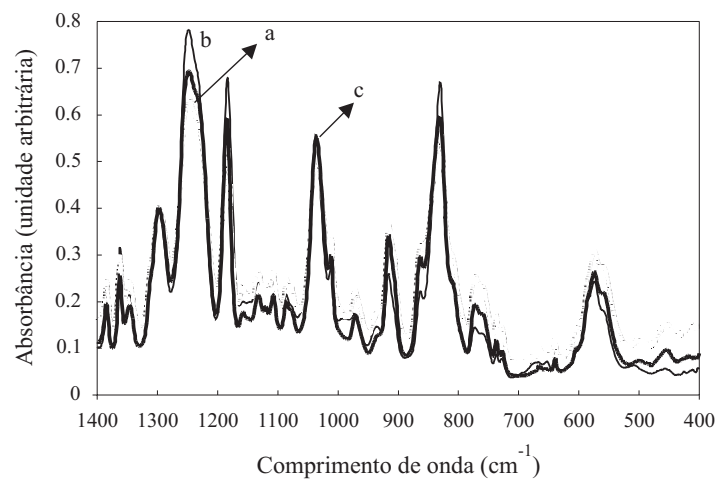

Figura 4. FTIR da resina pura (a) e das amostras correspondentes as Exp. № 1 e 2, normalizados pela banda a $1298 \mathrm{~cm}^{-1}$

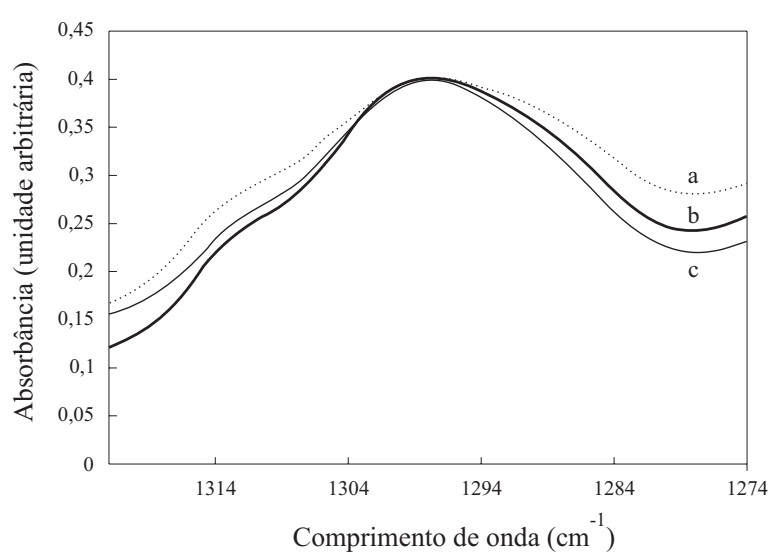

Figura 5a. FTIR da resina pura (a) e das amostras correspondentes as Exp. № 1 e 2., na região de $1298 \mathrm{~cm}^{-1}$

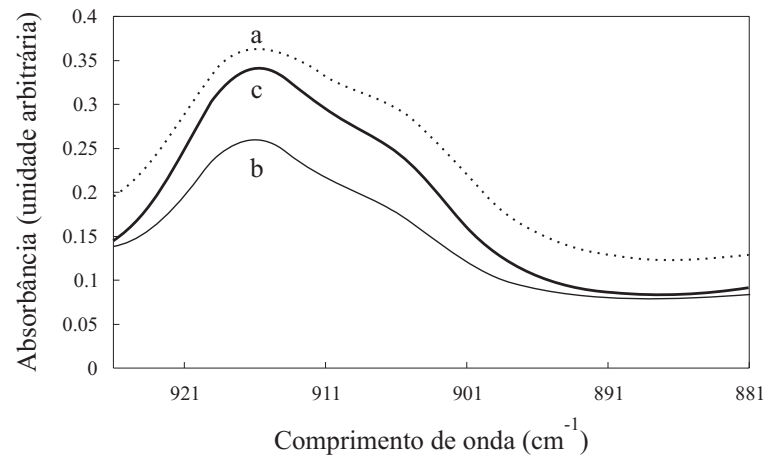

Figura 5b. FTIR da resina pura (a) e das amostras correspondentes as Exp. № 1 e 2, na região de $920 \mathrm{~cm}^{-1}$

copolímero em bloco ou graftizado, a partir da reação entre estes grupos funcionais. A mistura física também apresenta um pequeno decréscimo, porém não tão acentuado como no caso da polimerização "in situ". A diminuição de grupos epoxídicos nas misturas estudadas irão influenciar no processo de cura destes materiais, o que foi observado nas análises térmicas (TGA e DMTA) e nos testes mecânicos empregados neste trabalho.

\section{Análise termodinâmico-mecânica}

A temperatura de transição vítrea (Tg), o módulo de perda (E') e a $\tan \delta$ foram determinadas por análise dinâmico mecânica (DMTA), em corridas começando a temperatura ambiente até $200^{\circ} \mathrm{C}$.

As Figuras 6 e 7 mostram a dependência da tan $\delta$ com a temperatura, para amostras curadas com amina e anidrido, respectivamente. Pode-se observar que, em ambos os sistemas de cura, ocorre uma diminuição da Tg da matriz curada com a introdução da Pani Este comportamento pode estar associado à presença do DBSA na Pani, que atua como plastificante e também 


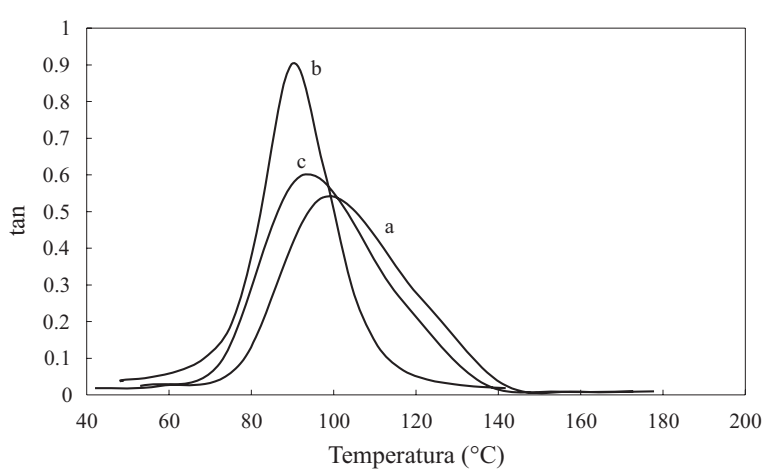

Figura 6. Dependência da $\tan \delta$ com a temperatura para amostras curadas com amina: (a) resina pura, (b) Exp. № 1 e (c) Exp. № 2.

ao consumo de grupos epoxídicos pelos grupos amina, o que ocasiona uma diminuição do numero de ligações cruzadas dos compósitos. Para a cura de todas as amostras, foi utilizada a razão estequiométrica epóxi/ amina e epóxi/anidrido de 1:1. Se parte dos grupos epoxídicos é consumido pelos grupos amina da Pani, o material possui um excesso de agente de cura (moléculas de baixo peso molecular) que também pode atuar como plastificante, diminuindo a Tg do material.

Outra característica é que a diferença entre as Tg's é maior entre os compósitos e a resina pura do que entre os compósitos preparados pelos dois processos citados. Com relação a tan $\delta$ ou pico de amortecimento, foi verificado um estreitamento da largura dos picos e maiores valores de $\tan \delta$ nos compósitos, em relação a resina pura nas amostras curadas com amina (Figura 6). Este comportamento indica que as moléculas presentes nos compósitos possuem maior mobilidade, o que confirma um menor numero de ligações cruzadas nestes materiais. As amostras curadas com anidrido não apresentam diferenças significativas na largura dos picos de $\tan \delta$, a não ser um pequeno aumento do valor de $\tan \delta$, associado também a aumento de mobilidade de cadeias.

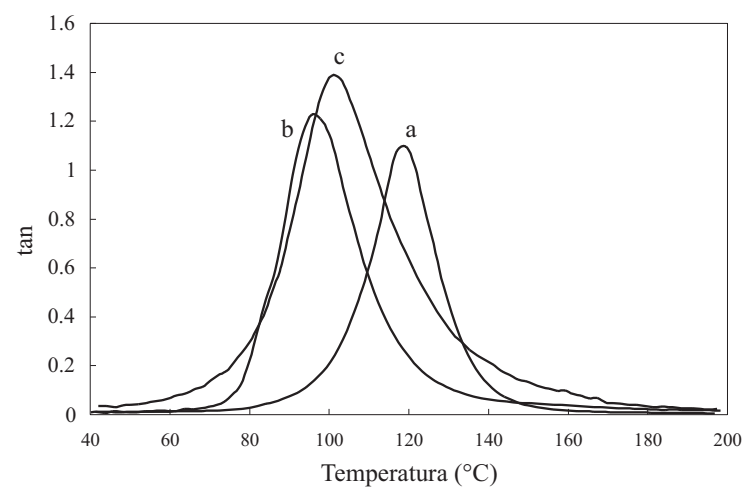

Figura 7. Dependência da $\tan \delta$ com a temperatura para amostras curadas com anidrido: (a) resina pura, (b) Exp. № 1 e (c) Exp. № 2

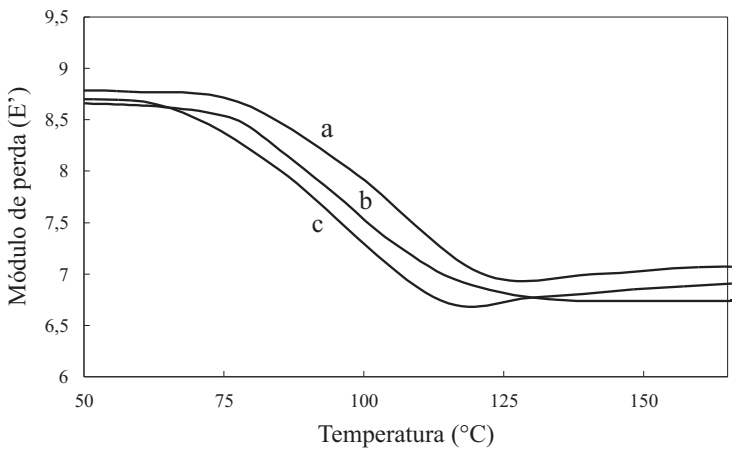

Figura 8. Módulo de perda (DMTA) das amostras curadas com amina: (a) resina pura; (b) Exp. № 1 e (c) Exp. № 2

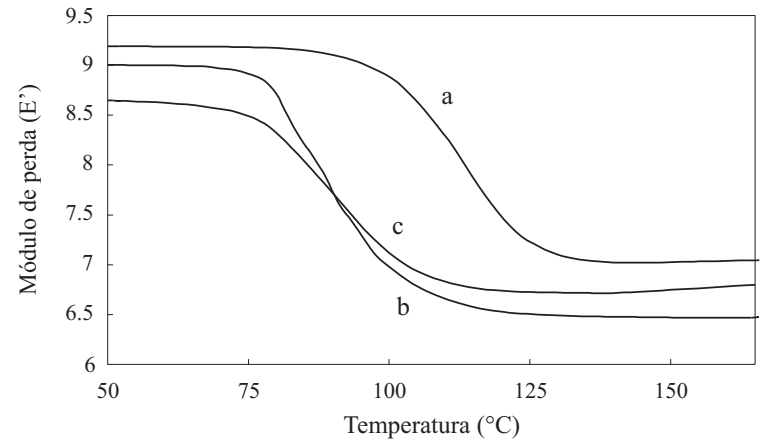

Figura 9. Módulo de perda (DMTA) das amostras curadas com anidrido: (a) resina pura, (b) Exp. $\mathrm{n}^{0} 1$ e (c) Exp. $\mathrm{n}^{0} 2$

Os valores de modulo de perda não variaram muito entre os dois diferentes tipos de compósitos e a resina pura, como pode ser visto nas Figuras 8 e 9. A diminuição do modulo nos compósitos, indica que a introdução da Pani na matriz de resina epoxídica ocasiona uma flexibilização da matriz, confirmando os resultados citados acima.

\section{Análise termogravimétrica}

A estabilidade térmica da resina epoxídica não curada, e das misturas preparadas a partir da polimerização "in situ" e da misturas física foi determinada por análise termogravimétrica (TGA), como mostra a Figura 10. Para todas as amostras é possível verificar uma pequena perda de massa abaixo de $100^{\circ} \mathrm{C}$, que pode ser associada a presença de moléculas de água adsorvidas nos materiais. Entre os três materiais analisados, a mistura preparada a partir da polimerização "in situ" (curva b) apresentou maior estabilidade térmica, com um segundo pico significativo ( $28 \%$ de perda de massa) na faixa de $350^{\circ} \mathrm{C}$. Este pico com perda de massa na faixa de $350^{\circ} \mathrm{C}$ pode ser associado à decomposição das moléculas graftizadas, que possuem maior peso mo- 


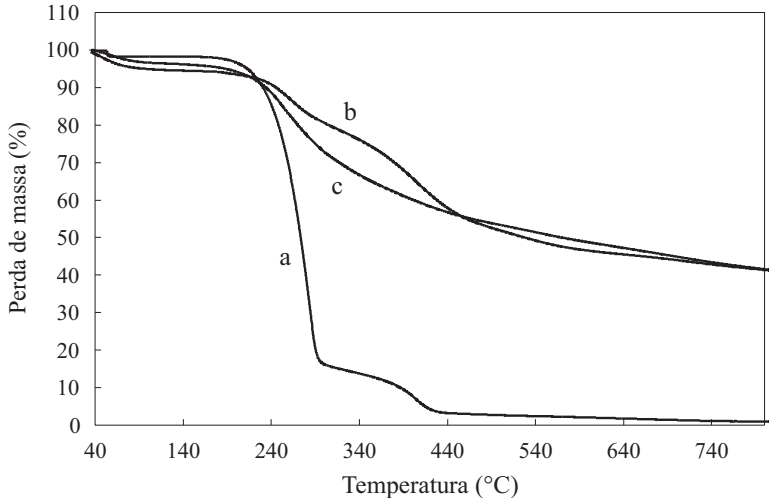

Figura 10. Curvas de TGA da (a) resina pura e das misturas Pani/epoxi preparadas (b) a partir da polimerização "in situ" e (c) a partir da mistura física.

lecular, ou mesmo devido a pequenos números de ligações cruzadas, promovida pela reação entre os grupos funcionais da Pani e da resina epoxídica.

\section{Propriedades mecânicas}

As propriedades mecânicas da resina pura e das misturas foram determinadas utilizando-se testes de tração e flexão. As Figuras 11 e 12 apresentam as curvas de tensão versus deformação, obtidas a partir dos ensaios de tração, para as amostras curadas com endurecedor do tipo amina e do tipo anidrido. As curvas apresentadas nessas Figuras, bem como nas Figuras 13 e 14, correspondem ao ensaio de um corpo de prova que apresentou resultado mais significativo da média dos valores encontrados. As misturas Pani/ epoxi apresentam valores de tensão máxima e energia necessária para ruptura menores do que aqueles observados para a resina pura. Este comportamento foi observado tanto para amostras curadas com endurecedor do tipo amina (Figura 11) como do tipo anidrido (Figura 12). Este comportamento era esperado, uma vez que a polianilina é um material

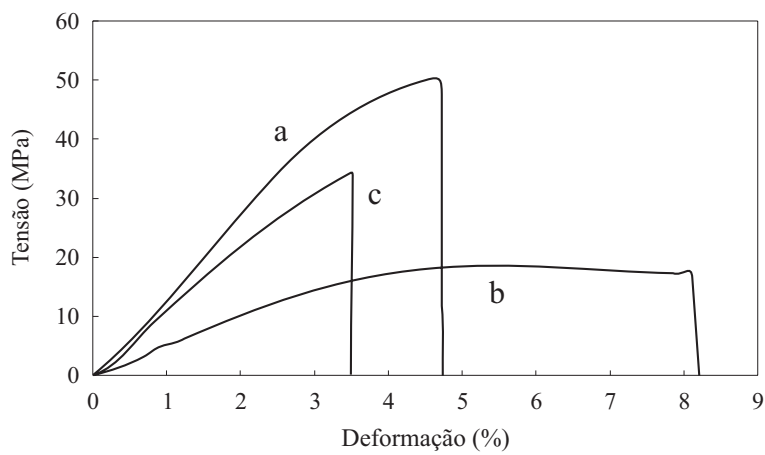

Figura 11. Curvas tensão versus deformação obtidas a partir de ensaios de tração para amostras curadas com amina(a) resina pura, (b) Exp. № 1 e (c) $\operatorname{Exp}$. № 2

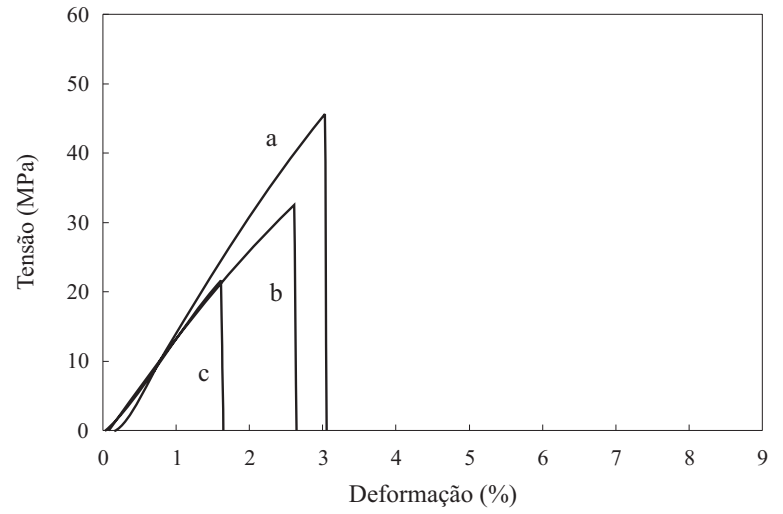

Figura 12. Curvas tensão versus deformação obtidas a partir de ensaios de tração para as amostras curadas com anidrido: (a) resina pura, (b) Exp. № 1 e (c) Exp. № 2

quebradiço com baixas propriedades mecânicas. Estas características são responsáveis pelos valores inferiores de tensão máxima e energia para o rompimento. As propriedades inferiores alcançadas na mistura preparada a partir da polimerização in situ (curva b), quando curada com o sistema do tipo amina podem ser atribuídas à presença de um excesso do agente de cura na amostra atuando neste caso como plastificante da rede de ligações cruzadas. No caso da mistura física, a reação de graftização entre a polianilina e a cadeia epoxídica é menos provável e com isso a proporção entre o endurecedor e os grupos epoxídicos se mantem quase constante. Conseqüentemente não surgem grandes mudanças na tensão máxima e no módulo. Os compósitos curados com anidrido apresentaram comportamento semelhante à resina epoxídica pura, como pode ser visto na Figura 12.

Os resultados obtidos no teste de flexão são apresentados nas Figuras 13 e 14 para amostras curadas com endurecedor do tipo amina e do tipo anidrido, respectivamente. Estes testes seguiram o

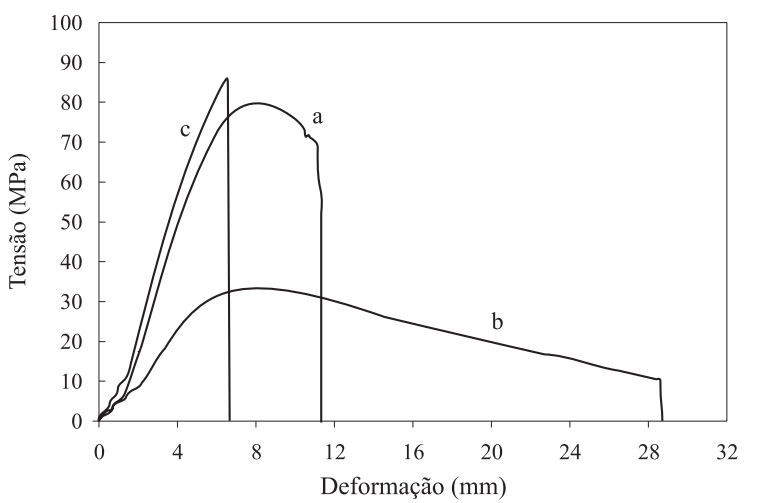

Figura 13. Curvas tensão versus deformação obtidas a partir de ensaios de flexão, para amostras curadas com amina: : (a) resina pura, (b) Exp. № 1 e (c) Exp. № 2 


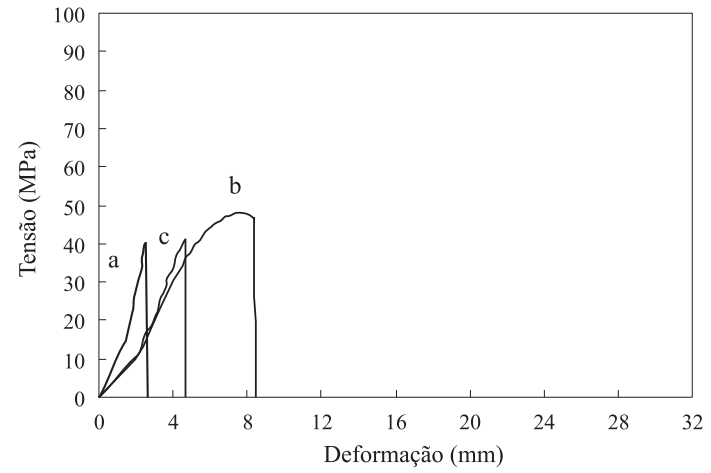

Figura 14. Curvas tensão versus deformaçãoobtidas a partir de ensaios de flexão para amostras curadas com anidrido: : (a) resina pura, (b) Exp. № 1 e (c) $\operatorname{Exp}$. № 2

comportamento de propriedade mecânica encontrado no teste de tração, com algumas pequenas diferenças. Os valores de tensão máxima das amostras curadas com amina, foram bem superiores aos obtidos com as amostras curadas com anidrido. Como nos testes de tração, a mistura obtida a partir da polimerização in situ (curva b), com tensão máxima de $33,40 \mathrm{MPa}$, apresentou o menor valor de tensão máxima. Entretanto, como pode ser visto na Figura 13, esta amostra alcançou maiores valores de deformação total, sendo que alguns corpos de prova não romperam. Isto indica uma maior flexibilidade desse material.

As amostras curadas com anidrido, novamente não apresentaram mudanças significativas na tensão máxima como mostra a Figura 14. A mistura preparada a partir da polimerização in situ (curva b) apresentou o melhor desempenho no que diz respeito ao teste de flexão, entre as amostras curadas com anidrido.

A tenacidade está associada à capacidade do material em resistir a fratura, tanto no inicio quanto na propagação, e pelo teste de flexão foi possível verificar o comportamento das amostras quanto a esta propriedade. Materiais mais tenazes necessitam de maior energia total para a fratura. Nas amostras curadas com amina, a tenacidade dos materiais diminui conforme diminui a energia para o rompimento entre a resina pura e as misturas físicas, respectivamente. A mistura Pani/epoxi obtida a partir da mistura física em solução, apesar de apresentar um alto valor de tensão máxima, não apresenta altos valores de tenacidade, indicando que este material é mais susceptível a dano por não poder resistir muito a formação de fissuras na matriz. Já nos compósitos curados com anidrido, a mistura obtidas a partir da polimerização "in situ” apresenta melhor desempenho mecânico, incluindo tenacidade, o que demonstra que esta amostra além de mais resistente a tensões flexivas é a mais tenaz.

\section{Conclusões}

Os compósitos epóxi/Pani obtidos por meio da polimerização do sal de anilina na presença da resina epóxi, apresentaram altos valores de condutividade elétrica, alcançando condutividades na ordem de $2 \times 10^{-3} \mathrm{~S} / \mathrm{cm}$, com a presença de apenas $7 \%$ em peso do aditivo condutor.

A polimerização in situ da anilina na presença de resina epoxídica deu origem a interações efetivas entre os componentes, com a formação de copolímeros em bloco ou graftizados que foram formados devido à capacidade dos grupos amina provenientes da polianilina reagirem com os grupos epoxídicos da matriz.

A mistura realizada a partir da polimerização in situ também resultou em um decréscimo na temperatura de transição vítrea da mistura. A diminuição dos valores do módulo, como visto nas analises de DMTA e nos testes mecânicos, é associada a um aumento da flexibilidade da matriz epoxídica curada, devido à natureza do contra-ion (DBSA) e do excesso de agentes de cura (amina ou anidrido).

Os testes mecânicos demonstraram que a presença da Pani na matriz curada de resina epoxídica tende a diminuir, em alguns casos, a resistência mecânica dos materiais. Entretanto, foi observado que se estes materiais contendo Pani forem empregadas em situações na qual não seja exigida a tensão máxima deles, a resistência mecânica deles estará acima da resina epoxídica pura.

\section{Agradecimentos}

Este trabalho só foi possível devido à ajuda financeira das seguintes agências de fomento: $\mathrm{CNPq}$, CNPq/PIBIC, FAPERJ PADCT-CNPq (Proc. no 620132/98-1), CEPG-UFRJ e CAPES.

\section{Referências Bibliográficas}

1. Ikkala, O. T.; Lindholm, T. M.; Ruohonenc, H.; Seläntausb, M.; Vakipartack, K. - Synth Met 69, 135 (1995).

2. Shacklette, L. W.; Han, C. C.; Luly, M. H. - Synth Met 55-57, 3532 (1993). 
3. Kitani, A.; Kaya, M.; Tsujioka, S.I.; Sasaki, K.; J. Polym. Sci Part A: Polym. Chem 26, 1531 (1988).

4. Anand, J; Palaniappan, S; Sathyanarayana, D.N. - Prog. Polym. Sci 23, 993 (1998).

5. Chiang, J.C.; MacDiarmid, A.G. - Synth Met 13,193 (1986).

6. Cao, Y.; Smith, P.; Heeger, A.J. - Synth Met 48, 91 (1992).

7. Ikkala, O.T.; Laakso, J.; Vakipartack, K.; Virtanen, E.; Ruohonen, H.; Jarvinen, H.; Taka, T.; Passiniemi, P.; Osterholm, J.E.; Cao, Y.; Andreatta, A.; Smith, P.; Heeger, AJ, Synth Met 69, 97 (1995).

8. Cao, Y.; Smith, P.; Heeger, A.J. - Synth Met 55-57, 3514 (1993).

9. Heeger, A. J. - Synth Met 55-57, 3471 (1993).

10. Zilberman, M.; Titelman, G. I.; Siegmann, A.; Haba, Y.; Narkis, M;. Alperstein, D. - J. Appl. Polym. Sci. 66, 243 (1997).

11. Leyva, M. E.; Barra, G. M. O.; Gorelova, M. M., Soares, B. G. - J. Appl. Polym. Sci 80, 626 (2001).

12. Davies, S. J.; Ryan, T. G.; Wilde, C. J.; Beyer, G. Synth Met 69, 209 (1995).

13. Barra, G. M. O.; Leyva, M. E.; Soares, B. G.; Mattoso, L. H.; Sens, M. - J. Appl. Polym. Sci 82, 114 (2001).

14. Faez, R.; De Paoli, M. A. - Eur. Polym. J37, 1139 (2001).

15. Vallim, M. R.; Felisberti, M. I.; De Paoli, M. A., J. Appl. Polym. Sci 75, 677 (2000).
16. Faez, R.; Gazotti, W. A.; De Paoli, M. A. - Polymer 40, 5497 (1999).

17. Cao,Y.; Treacy, G. M.; Smith, P.; Heeger, A. J. - Synth Met 55-57, 3526 (1993).

18. Oh, S. Y.; Koh, H. C.; Choi, J. W.; Thee, H. W.; Kim, H. S. - Polym. J, 29, 404 (1997).

19. Jeon, B. H.; Kim, S.; Choi, M. H.; Chung, I. J. - Synth Met 104, 95 (1999)

20. Xie, H. Q.; Ma, Y. M.; Guo, J. S. - Polymer 40,261 (1998).

21. Ruckenstein, E.; Sun, Y. - Synth Met, 74,107 (1995).

22. Barcia, F. L.; Soares, B. G. - Anais do Congresso Latino Americano de Polimeros, Cuba. pp276 (2000).

23. Bagheri, R.; Williams, M. A.; Pearson, R.A. - Polym. Engin. Sci., 37, no2, 245 (1997).

24. Cassignol,C.; Cavarero, M.; Boudet, A; Ricard, A. Polym. 40, 1139 (1999).

25. Fournier, J.; Boiteux, G.; Seytre, G.; Marichy, G. - Synth Met 84, 839 (1997).

26. Talo, A.; Passiniemi, P.; Forsen, O.; Ylasaari, S. - Synth Met 85, 1333 (1997).

27. Jeevanada, T.; Palaniappan, S.; Siddaramaiah - J. Appl. Polym. Sci. 74, 3507 (1999).

Recebido: 27/09/01 Aprovado:11/10/01 